\title{
Anemia and Iron Deficiency Anemia in High School Girls in Nakhon Si Thammarat, Thailand
}

Orawan Sarakul, Ph.D.*, Manas Kotepui, Ph.D., Ranee Marasa, B.Sc., Waehafeeyah Thepwarin, B.Sc.

School of Allied Health Sciences, Walailak University, Thasala, Nakhon Si Thammarat 80160, Thailand.

Received 26 January 2018 • Accepted 24 April 2018 • Published online 3 August 2018

\section{Abstract:}

Objective: To determine the prevalence and causes of anemia in high school girls in Nakhon Si Thammarat, Thailand. Material and Methods: This cross-sectional study was performed in high school girls aged 15-18 years old. Blood samples were collected for hematological parameters, iron profiles and blood smear examination. The recall 24-hour dietary data were collected using a questionnaire to determine and calculate daily iron intake. For purposes of the study, anemia was defined as hemoglobin $(\mathrm{Hb})$ of $<12 \mathrm{~g} / \mathrm{dL}$ and iron deficiency anemia (IDA) was defined as $\mathrm{Hb}$ of $<12 \mathrm{~g} / \mathrm{dL}$ with serum ferritin (SF) of $<15 \mu \mathrm{g} /$.

Results: The results show that in 19 of a total of 227 subjects (8.3\%) anemia was present. Iron deficiency was the main cause of anemia (13 of 19 cases) with a prevalence of $5.7 \%$, while the prevalence of anemia due to other causes was $3.6 \%$ (6 of 19 cases). Iron deficiency without anemia was found in 36 cases (15.9\%). Participants' daily iron intake was less than the recommended $15 \mathrm{mg}$ per day.

Conclusion: The present study indicates that iron deficiency is the most common cause of anemia in adolescent girls in Thailand. Health care programs in the schools should consider dietary behavior in order to reduce the prevalence of IDA in young women.

Keywords: adolescence, anemia, iron deficiency

Contact: Orawan Sarakul, Ph.D.

School of Allied Health Sciences, Walailak University, Thasala,

Nakhon Si Thammarat 80160, Thailand.

E-mail: sorawan@mail.wu.ac.th
J Health Sci Med Res 2018;36(3):197-204 DOI: http://dx.doi.org/10.31584/jhsmr.2018.36.3.11 www.jhsmr.org 


\section{Introduction}

Anemia is a common public health problem which can occur in people of all ages. ${ }^{1,2}$ Because iron is the main component of hemoglobin, iron deficiency is the most common cause of nutrient deficiency anemia. The depletion of iron is correlated with hemoglobin reduction. ${ }^{3}$ Iron deficiency can be caused by many factors, including insufficient iron consumption and chronic blood loss, which may be caused by parasitic infections, menstruation or chronic gastritis. In adolescent girls, restriction or improper nutrient intake and menstruation are important factors that may induce iron deficiency. ${ }^{4-9}$ Iron deficiency anemia (IDA) is usually asymptomatic in the early stages because iron is present in physiological stores; when an iron deficiency progresses, various symptoms will occur that can lead to health problems such as anemia, and cognitive and reproductive impairment. ${ }^{10}$

In 2005, the World Health Organization (WHO) reported that the global prevalence of anemia in nonpregnant women aged $15-50$ years old was $30.2 \%$. The prevalence in Asia was 33.0\%, which was higher than other areas. ${ }^{11}$ The prevalence of anemia was still high in this population in 2011, when prevalence was $29.0 \%$ worldwide, but $41.5 \%$ in Southeast Asia and $24.0 \%$ in the Thai population. $^{2}$ The most common cause of anemia was IDA, especially in developing country. Higher prevalence of IDA was reported more often in non-industrialized than in industrialized countries. Moreover, IDA is higher in prevalence in women than men due to blood loss during menstruation and increased iron requirements during pregnancy.,12

This study aims to determine the prevalence of anemia and IDA among healthy high school girls in Nakhon Si Thammarat, Thailand. Daily dietary iron intake from the recall data was calculated using the Nutrisurvey Program. Preliminary data from this study will serve as a guideline for anemia prevention and treatment programs.

\section{Material and Methods}

\section{Subjects}

The cross-sectional study was conducted from August to December 2013. The subjects of the study were 227 healthy high school girls from a school in Nakhon Si Thammarat, Thailand. The inclusion criteria in the study were healthy, female volunteers, aged between 15 and 18 years old, from all the high school's classes (total $n=450$ ). The sample size was calculated using the estimated population from the prevalence of anemia in the previous report. ${ }^{2}$ Participants' demographic data and daily dietary data were collected using a questionnaire to determine and calculate daily iron intake. The method for dietary recall data collection and calculation was published in the previous study. ${ }^{13}$ Briefly, the daily iron intake from food was calculated from the 24-hour dietary recall data. The tools for dietary recall data included pictures of food. Measurement tools such as tablespoons and cups were used to indicate size and method of preparation. The 24-hour iron intake was calculated using the Nutrisurvey Program. Students who did not complete the questionnaire and those who had a family history of genetic disorders, such as thalassemia or chronic diseases, were excluded. This study was approved by the Ethics Committee of Walailak University, Thailand (Ref no.14/048).

\section{Blood sample collection}

A total of $6 \mathrm{~mL}$ of venous blood was collected from 227 subjects, $3 \mathrm{~mL}$ for Ethylenediaminetetraacetic acid (EDTA) blood and $3 \mathrm{~mL}$ of clotted blood for serum preparation. EDTA blood samples were used for hematological parameters analysis. Serum samples were used for iron profile evaluation.

\section{Hematological parameters}

EDTA blood samples were tested for hematological parameters using NIHON KOHDEN MEK8222 
(Tokyo, Japan). Parameters included red blood cell (RBC) count, hemoglobin $(\mathrm{Hb})$, hematocrit $(\mathrm{Hct})$, mean corpuscular volume (MCV), mean corpuscular hemoglobin $(\mathrm{MCH})$, mean corpuscular hemoglobin concentration $(\mathrm{MCHC})$ and red cell distribution width (RDW).

\section{Iron profile study}

To determine the iron status of subjects, serum samples were tested for serum iron (SI), total iron binding capacity (TIBC), and \% transferrin saturation (\%TS) was calculated. Serum ferritin (SF) was determined based on luminescent immunoassay using VITROS ECi/ECiQ Immunodiagnostic Systems (Ortho-Clinical Diagnostics, Inc, New York, United States). SI and TIBC were detected using the iron liquid color cleaning factor colorimetric agarbased (CAB) method (Human, Taunusstein, Germany).

\section{Guidelines for anemia interpretation}

The guidelines for anemia, iron deficiency without anemia and IDA were defined as follows: anemia - $\mathrm{Hb}<12$ $\mathrm{g} / \mathrm{dL}$; iron deficiency without anemia $-\mathrm{SF}<15 \mu \mathrm{g} \Lambda$ with $\mathrm{Hb} \geq 12 \mathrm{~g} / \mathrm{dL} ;$ IDA - $\mathrm{Hb}<12 \mathrm{~g} / \mathrm{dL}$ with $\mathrm{SF}<15 \mu \mathrm{g} /{ }^{14}$

\section{Statistical analyses}

The data were analyzed using the Statistical Package for Social Science (SPSS) for Windows, version 17.0. A Kolmogorov-Smirnov test was used to determine the normality of distribution. A Mann-Whitney $U$ test was used to compare the differences in parameters between the groups. A p-value of $<0.05$ was considered significant.

\section{Results}

General subjects data from the questionnaire and hematological parameters

Two hundred twenty-seven high school girls aged 15-18 years participated in the study; $82.4 \%$ were Buddhist,
$16.3 \%$ Muslim, and $1.3 \%$ Christian. The percentage of participants who had a menstrual period of more than five days was $59.1 \%$, and of less than five days it was $40.9 \%$. Iron intake was calculated from food intake per day. Of the participants, iron intake in $97.6 \%$ was less than the recommended $15 \mathrm{mg} /$ day (Table 1). The hematological parameters are shown in means \pm standard deviation (S.D.) RBC count was $4.8 \pm 0.4 \times 10^{6} / \mu \mathrm{L}, \mathrm{Hb}$ was $13.5 \pm 1.3 \mathrm{~g} / \mathrm{dL}$, Hct was $40.0 \pm 4.5 \%$, MCV was $83.0 \pm 3.0 \mathrm{fL}, \mathrm{MCH}$ was $28.2 \pm$ $3.1 \mathrm{pg}, \mathrm{MCHC}$ was $33.8 \pm 0.8 \mathrm{~g} / \mathrm{dL}$ and RDW was $12.3 \pm 1.3 \%$ (Table 2).

Table 1 Demographic data from the questionnaire of total 227 participants

\begin{tabular}{ll} 
Demographic category & Number (\%) \\
\hline Age (years) & \\
15 & $8(3.6)$ \\
16 & $78(34.4)$ \\
17 & $102(45.0)$ \\
18 & $39(17.0)$ \\
Religion & \\
Buddhist & $187(82.4)$ \\
Muslim & $37(16.3)$ \\
Christian & $3(1.3)$ \\
Body weight (kg) & \\
$30-50$ & $132(58.3)$ \\
$51-70$ & $88(38.9)$ \\
$71-90$ & $7(2.8)$ \\
Period time of menstruation (days) & \\
$<5$ & $134(59.1)$ \\
$\geq 5$ & $93(40.9)$ \\
Iron intake calculated from food per day (mg) & \\
$<15$ & $222(97.6)$ \\
$\geq 15$ & $5(2.4)$ \\
\hline
\end{tabular}


Table 2 Hematological parameters of 227 subjects

\begin{tabular}{llll}
\hline Hematological parameters & Number (cases) & Normal value & Mean \pm S.D. \\
\hline $\mathrm{RBC}$ count $\left(\times 10^{6} / \mu \mathrm{L}\right)$ & 227 & $4.1-5.1$ & $4.8 \pm 0.4$ \\
$\mathrm{Hb}(\mathrm{g} / \mathrm{dL})$ & 227 & $12.0-16.0$ & $13.5 \pm 1.3$ \\
$\mathrm{Hct}(\%)$ & 227 & $36.0-46.0$ & $40.0 \pm 4.5$ \\
$\mathrm{MCV}(\mathrm{fL})$ & 227 & $80.0-100.0$ & $83.0 \pm 8.0$ \\
$\mathrm{MCH}(\mathrm{pg})$ & 227 & $25.0-35.0$ & $28.2 \pm 3.1$ \\
$\mathrm{MCHC}(\mathrm{g} / \mathrm{dL})$ & 227 & $31.0-37.0$ & $33.8 \pm 0.8$ \\
$\mathrm{RDW}(\%)$ & 227 & $11.0-15.0$ & $12.3 \pm 1.3$ \\
\hline
\end{tabular}

S.D.=standard deviation, RBC=red blood cell, $\mathrm{Hb}=$ hemoglobin, $\mathrm{Hct=hematocrit,} \mathrm{MCV}=$ mean corpuscular volume, $\mathrm{MCH}=$ mean corpuscular hemoglobin, $\mathrm{MCHC}=$ mean corpuscular hemoglobin concentration, $\mathrm{RDW}=$ red cell distribution width

\section{Prevalence of anemia, iron deficiency and IDA}

The prevalence of anemia was found to be $8.3 \%$ in study subjects. Of the participants, $21.6 \%$ had an iron deficiency, $15.6 \%$ were iron deficient without anemia, $5.7 \%$ had IDA, and $2.6 \%$ had anemia from other causes (Table 3 ). However, iron intake and the period of menstruation of the participants who had IDA did not differ significantly from the participants who had anemia by the other causes.

Differences in blood parameters between IDA and iron deficiency without anemia were statistically tested. It was found that all hematological parameters in the group with iron deficiency without anemia were significantly higher than in the IDA group ( $p$-value<0.05). Iron profiles show the same pattern: in the group with iron deficiency without anemia SI, TS and SF were significantly higher than in the IDA group ( $p$-value<0.05). Only the TIBC of the IDA group was higher than in the group with iron deficiency without anemia (Table 3). Moreover, the SF value was significantly correlated with the other iron profiles ( $p$-value< 0.05). In addition, the iron profiles of the IDA group differed significantly from those of the group with anemia from other causes ( $p$-value<0.05). The RBC morphology study of the IDA group showed that $76.9 \%$ of this group had hypochromic microcytic RBC and no thalassemic blood picture was found.

\section{Discussion}

This study reports the prevalence of anemia, iron deficiency, IDA and anemia from other causes in 227 high school girls in Nakhon Si Thammarat, Thailand. The prevalence of anemia is consistent with a previous report on female students $15-18$ years of age. ${ }^{15}$ Iron deficiency is the main cause of anemia in the participants of this study with $68.4 \%$ having IDA. The prevalence of IDA in this study is higher than the findings from other studies reported by research groups in northeast Thailand and in female adolescents in Laos. ${ }^{6,16,17}$ The differences in lifestyles, behavior and types of diet are posed as possible causes of this finding. In addition, thalassemia was found to be a highly prevalent cause of anemia in the northeast and Laos. ${ }^{16-19}$ Insufficient iron intake and blood loss were reported as the factors leading to iron deficiency., ${ }^{5,6,20}$ This study showed that iron intake from food did not differ among the groups with IDA and others. However, other possible causes may be involved, such as the biological effects of tannic acid from drinking coffee and tea after meals, which inhibits iron 


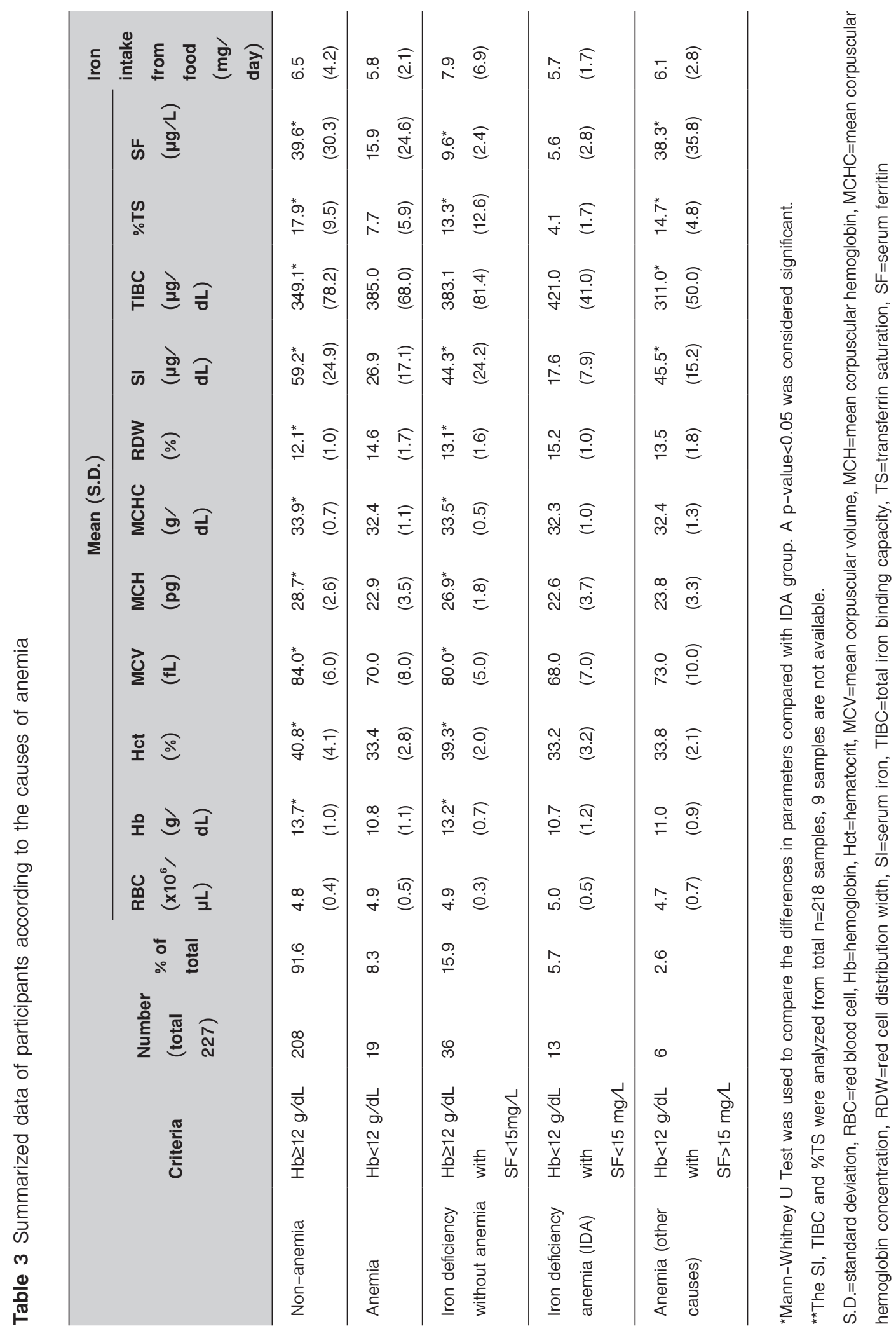


absorption. The information from the questionnaire indicates that most of the participants did not know about the inhibitory effect of tea and coffee on iron absorption (data not shown). ${ }^{21,22}$ In addition, menstruation was not significantly correlated with IDA. This finding differs from a previous study in female Muslim students aged 13-15 years. ${ }^{5}$ It may have resulted from the limitations of the menstruation evaluation tool used in this study, which determined only the duration but did not include the amount of blood loss.

The red blood cell morphology of cases with IDA in this study was shown to be hypochromic microcytic, which correlates with $\mathrm{MCV}$ and $\mathrm{MCHC}$ values. As iron is a key component of hemoglobin, insufficient iron content affects hemoglobin production, which leads to hypochromic microcytic RBC. On the other hand, $2.6 \%$ of the subjects in the study had anemia from other causes. This group had iron profiles in the normal range. Nevertheless, this study has some limitations. The screening of thalassemia was not performed and blood picture did not indicate severe thalassemia. However, the subjects with thalassemia traits may have had only mild anemia and no specific signs and symptoms. Therefore, thalassemia may be a cause of anemia in this group, given its high incidence in the south of Thailand. ${ }^{23}$ Moreover, SF is an acute phase protein, which is markedly elevated in inflammations. ${ }^{24,25}$ The SF in IDA persons who had an inflammation may be overestimated. Unfortunately, the factors for determining inflammations were not detected in this study. Hence, the prevalence of IDA may be higher than reported.

The effectiveness of health promotion programs used to improve nutritional consumption behavior and IDA prevention has been reported in many countries, such as Australia, UK and in Thailand also.,9,14,26,27 Although the prevalence of anemia and iron deficiency in this study was low, and calculated in only one school, it will serve as important feedback for the improvement of health promotion programs. Health promotion programs for adolescents should be added to the school policy. The leaders of the program should set the goals. The program should consist of providing knowledge about the causes of anemia and healthy food for students and all related persons. The nutrition of school lunch menus should be considered. Dietary behavior, parasitic infection and personal diseases, such as gastrointestinal bleeding, are important factors for evaluating the possible causes of IDA. Iron-rich foods, such as meat, liver, blood curd, vegetables and other nutrients, including vitamin $\mathrm{C}$, which support iron absorption, should be provided. Moreover, the consumption of food that inhibits iron absorption, such as tea, coffee, milk and cereal, should be advised against. ${ }^{21}$ For IDA cases, an iron supplement should be given and followed up. Annual health checks that include screening for anemia should be added to the program. Importantly, the contribution of students in program planning will drive the success of the program.

\section{Conclusion}

This report shows the prevalence of anemia, mostly caused by iron deficiency, in high school girls, 15-18 years of age, in Nakhon Si Thammarat, Thailand. Adolescent girls should be urged to consume a diet sufficient in iron in order to achieve optimal health. Moreover, a health promotion program should be instituted in schools for anemia prevention and to improve the quality of life of young women in susceptible populations.

\section{Acknowledgement}

This study was financially supported by the Institute of Research and Innovation, Walailak University. We would like to thanks the subjects who participated in this study. 


\section{References}

1. Milman N. Anemia-still a major health problem in many parts of the world. Ann Hematol 2011;90:369-77.

2. World Health Organization. The global prevalence of anemia in 2011. Geneva: WHO; 2015.

3. Ahmed F, Khan MR, Banu CP, Qazi MR, Akhtaruzzaman M The coexistence of other micronutrient deficiencies in anaemic adolescent school girls in rural Bangladesh. Eur $\mathrm{J}$ Clin Nutr 2008;62:365-72.

4. Maenpuen S, Muktabhant B, Thavornpitak Y. Iron deficiency anemia and energy and nutrients intake of vegetarian adolescents in Ratchatani Asoke community, Ubon Ratchathan province. Srinagarind Med J 2009;24:314-20.

5. Hayeemad S, Pradipasen M, Satheannoppakao W, Kaseamsub R. Dietary pattern and factors associated with anemia among female adolescents in Islam private schools. The $2^{\text {nd }}$ International Conference on Humanities and Social Sciences; 2010 April 10; Faculty of Liberal Arts, Prince of Songkla University, Songkhla, Thailand; 2010.

6. Inthavong S, Sanchaisuriya K, Chaitripop C, Phengdy B, Sanchaisuriya P, Fucharoen G, et al. Prevalence and risk factors for anemia, iron deficiency and iron deficiency anemia among female children and adolescents in Vientiane, Lao People's Democratic Republic. J Med Tech Phy Ther 2014;26: 141-9.

7. Pasricha SRS, Flecknoe-Brown SC, Allen KJ, Gibson PR, McMahon LP, Olynyk JK, et al. Diagnosis and management of iron deficiency anaemia: a clinical update. Med J Australia 2010;193:525-32.

8. Johnson-Wimbley TD, Graham DY. Diagnosis and management of iron deficiency anemia in the $21^{\text {st }}$ century. Therap Adv Gastroenterol 2011;4:177-84.

9. Winichagoon P. Prevention and control of anemia: Thailand experiences. J Nutr 2002;132(Suppl 4):S862-6.

10. Jauregui-Lobera I. Iron deficiency and cognitive functions. Neuropsychiatr Dis Treat 2014;10:2087-95.

11. McLean E, Cogswell M, Egli I, Wojdyla D, Benoist B. Worldwide prevalence of anaemia, WHO Vitamin and Mineral Nutrition Information System, 1993-2005. Public Health Nutr 2009;12: 444-54.

12. Chaksai J, Soiwo N, Sanchaisuriya P, Sarakarn P, Sanchaisuriya
K. Anemia in working age: a retrospective-cohort study. J Med Tech Phy Ther 2012;24:135-42.

13. Kotepui M, Sarakul O, Uthaisar K, Marasa R, Thepwarin W. Dietary intake of high school girls aged 15-18 years in Nakhon Si Thammarat province, Thailand. J Health Res 2016;30:75-81.

14. Goddard AF, James MW, Mclntyre AS, Scott BB. Guidelines for the management of iron deficiency anaemia. Gut 2011;60: 1309-16.

15. Kongsomboon K, Hutspardol S, Wongjitrat N, Chansakulporn S. Anemia of students in Ongkharak district, Nakhon Nayok province according to nutritional status, age groups and gender: cross sectional study. J Med Health Sci 2006;13:225-33.

16. Panomai N, Sanchaisuriya K, Yamsri S, Sanchaisuriya P, Fucharoen G, Fucharoen S, et al. Thalassemia and iron deficiency in a group of northeast Thai school children: relationship to the occurrence of anemia. Eur J Pediatr 2010;169:1317-22.

17. Thurlow RA, Winichagoon P, Green T, Wasantwisut E, Pongcharoen $\mathrm{T}$, Bailey $\mathrm{KB}$, et al. Only a small proportion of anemia in northeast Thai school children is associated with iron deficiency. Am J Clin Nutr 2005;82:380-7.

18. Yanola J, Kongpan C, Pornprasert S. Prevalence of anemia, iron deficiency, thalassemia and glucose-6-phosphate dehydrogenase deficiency among hill-tribe school children in Omkoi district, Chiang Mai province, Thailand. Southeast Asian J Trop Med Public Health 2014;45:920-5.

19. Kulaphisit M, Kampuansai J, Leecharoenkiat K, Wathikthinnakon M, Kangwanpong D, Munkongdee $T$, et al. A comprehensive ethnic-based analysis of alpha thalassaemia allelle frequency in northern Thailand. Sci Rep 2017;7:4690.

20. Alam N, Roy SK, Ahmed T, Ahmed AM. Nutritional status, dietary intake, and relevant knowledge of adolescent girls in rural Bangladesh. J Health Popul Nutr 2010;28:86-94.

21. Jaramillo A, Briones L, Andrews M, Arredondo M, Olivares M, Brito $A$, et al. Effect of phytic acid, tannic acid and pectin on fasting iron bioavailability both in the presence and absence of calcium. J Trace Elem Med Biol 2015;30:112-7.

22. Andrews M, Briones L, Jaramillo A, Pizarro F, Arredondo M. Effect of calcium, tannic acid, phytic acid and pectin over iron uptake in an in vitro Caco-2 cell model. Biol Trace Elem Res 2014;158:122-7. 
23. Nuinoon M, Kruachan K, Sengking W, Horpet D, Sungyuan $U$. Thalassemia and hemoglobin $E$ in southern Thai blood donors. Adv Hematol 2014;932306.

24. Namaste SM, Rohner F, Huang J, Bhushan NL, Flores-Ayala R, Kupka R, et al. Adjusting ferritin concentrations for inflammation: Biomarkers Reflecting Inflammation and Nutritional Determinants of Anemia (BRINDA) project. Am J Clin Nutr 2017; 106(Suppl 1):S359-71.
25. Suchdev PS, Williams AM, Mei Z, Flores-Ayala R, Pasricha SR, Rogers LM, et al. Assessment of iron status in settings of inflammation: challenges and potential approaches. Am J Clin Nutr 2017;106(Suppl 6):S1626-33.

26. Trowbridge F. Prevention and control of iron deficiency: priorities and action steps. J Nutr 2002;132(Suppl 4):S880-2.

27. Trowbridge F, Martorell R. Summary and recommendations. J Nutr 2002;132(Suppl 4):S875-9. 